\title{
Social Media - The Newest Doctor in Town
}

\author{
Ohsin Behl \\ Intern, Maharashtra Institute of Medical Education and Research, Pune \\ Maharashtra University of Health Sciences. \\ E-mail- officialobehl@gmail.com
}

\section{INTRODUCTION}

What was the absolutely first thing you did this morning? Before you got up from bed even? I have to admit that I did the same thing. In fact, 197 million others are just like you [1]. You probably saw a bunch of 'good morning' and 'good thought' forwards from your relatives. But occasionally there's that one uncle with a self-proclaimed medical degree that'll invariably send forwards like "Cholesterol is good for you". We're obviously too busy to deal with all these nonsense messages so we ignore it. But the less occupied people read it and say "What! I can have that samosa without any guilt? This has to be true", and it goes on in a cascade because of a "non-fact checking" culture, till somewhere a patient of dyslipidemia stops going to his doctor because who likes taking Atorvastatin every day? And it's not just laymen, even the people who are responsible for health policy decisions have been found to be not just unaware, but wrongly aware of facts [2-3]. This is the power of social media. And it's all around us. And it feeds the fundamental human characteristic: gossip. Our brains have been wired to rely on word of mouth, and to be more alarmed by "dramatic things", because there was a time when that was the only mode of communication [3].

What looks more eye catching? "Alcohol consumption leads to liver cirrhosis" (research article) or "10 ways that wine and beer are good for you" (click bait). Not just a simple observation, this is a research based fact that false news spreads much faster than the truth [4-5]. In an international study, in the case of food and nutrition articles, only 5 out of 18 articles studied for credibility received a positive credibility rating [5]. Content in this category was quite varied, but generally articles often took an extreme stand, often exaggerating the benefits and harms of various foods [5]. In the case of articles about vaccines, 12 articles received a positive credibility ratings. We observed that more than half of these articles were reporting outbreaks of vaccine-preventable diseases (mainly measles). These outbreaks were the result of declining vaccine uptake due to antivaccination movements. The fact that these articles are popular reflects the general public's concern about this issue. Further underscoring this issue is the World Health Organization branding vaccine hesitancy - mainly due to the anti-vaccination movement - as one of the top threats to global health in 2019 [5]. All 5 vaccine articles which received a negative credibility rating were anti-vaccine in nature, invoking conspiracy theories about public health authorities and pharmaceutical companies, as well as persistent myths about vaccines which have been disproven [5].

In 2018, the number one article shared more than a million times was a piece titled "Federal Study Finds Marijuana 100X Less Toxic Than Alcohol, Safer Than Tobacco - Your Health Guide" [2] was rated a NEGATIVE 1.3 in credibility, meaning that it was not credible and potentially harmful. But is it really a Public health issue? Just like herd immunity and antibiotic resistance, this false news epidemic needs public awareness. And as medical professionals, it becomes our responsibility to not just leave our stethoscope in the hospital. Our responsibility doesn't stop at curing patients. It is our duty to stop this at the root, especially when the branches span to $14 \%$ of this country's population [1]. And because false news spreads faster than real facts, we have to be all the more proactive as the knowledge bearers of our community. What use are those 5.5 years 
of knowledge if the people around us are being misled by Whatsapp forwards and Facebook posts and Instagram stories.

I have to admit that there have been times when I have found myself questioning whether my own knowledge is credible, and that is how these articles are designed, such as an image of a blister pack of pills, warning recipients to avoid certain brands of the pain reliever acetaminophen because "doctors advise that it contains 'Machupo' virus, one of the most dangerous viruses in the world, with a high mortality rate" [4]. But do not hesitate to refer to the thousands of research articles you can find on PubMed and ResearchGate. Take the time to educate people around you, and correct their knowledge with scientific backing. Our small effort can stop a social media epidemic, even save a few doctors from being harassed by their misinformed patients, and may save a life in time of need.

We have the whole world on our fingertips, and it's up to us to use it for good.

\section{REFERENCES}

1. Kumar P. India will have 730 million internet users by 2020, govt says | India News - Times of India [Internet]. The Times of India. [cited 2019Jun18]. Available from: http://www.timesofindia.indiatimes.com/india/india-will-have-730-million-internet-users-by2020-govt-says/articleshow/57858869.cms

2. Regan J. Federal Study Finds Marijuana 100X Less Toxic Than Alcohol, Safer Than Tobacco [Internet]. Your Health Guide. 2018 [cited 2019Jun18]. Available from: https://web.archive.org/web/20180401034419/http://urhealthguide.com/federal-study-findsmarijuana-100x-less-toxic-alcohol-safer-tobacco/

3. Rosling H, Rosling O, Rönnlund Anna Rosling. Factfulness: ten reasons were wrong about the world and why things are better than you think. Londres: Sceptre; 2018.

4. Sachdev C. Fake Medical News Can Now Be Fact-Checked In India [Internet]. NPR. NPR; 2017 [cited 2019Jun18]. Available from: https://www.npr.org/sections/goatsandsoda/2017/05/12/526687362/fake-medical-news-cannow-be-fact-checked-in-india

5. The Most Popular Health Articles of 2018, a Scientific Credibility Review [Internet]. Health Feedback. 2019 [cited 2019Jun18]. Available from: https://healthfeedback.org/the-most-popularhealth-articles-of-2018-a-scientific-credibility-review/\#F1

6. Zhang AX, Robbins M, Bice E, Hawke S, Karger D, Mina AX, et al. A Structured Response to Misinformation. Companion of the The Web Conference 2018 on The Web Conference 2018.

Acknowledgements - Nil

Source of Funding - Nil

Conflict of Interest $-\mathrm{Nil}$ 